\title{
FEATURES OF SEXUAL NERVOUSNESS OF MEN AND WOMEN
}

\author{
VIKTORIYA HUPALOVSKA \\ Department of Psychology, Faculty of Philosophy, \\ Ivan Franko National University of Lviv \\ Universytetska, 1, Lviv, Ukraine \\ E-mail address: Viktoriya.Hupalovska@Inu.edu.ua \\ ORCID: https://orcid.org/0000-0002-5994-2102 \\ IRYNA KOCHERHINA \\ Department of Psychology, Faculty of Philosophy, \\ Ivan Franko National University of Lviv \\ Universytetska,1, Lviv, Ukraine \\ E-mail address: Iryna.Kocherhina@Inu.edu.ua \\ ORCID: https://orcid.org/0000-0002-8699-0601
}

\begin{abstract}
Aim. The aim is to present the results of research on the sexual nervousness of men and women.

Methods. 87 Ukrainian men and women were interviewed. For the analysis of the obtained results, methods of statistical processing of data were used.

Results. It has been established that there are differences between men and women in terms of sexual nervousness, attitudes towards pornographic materials, sexual arousal, friendly and exchange approaches to sex, signs of positive relationships with others and self-acceptance. Men are more focused on careful approach to sex and women on friendly approach. Men are more loyal to pornographic products and reach sexual arousal faster. They have higher levels of sexual nervousness. For both men and women, sexual satisfaction is related to a reduction in sexual nervousness and an increase in a sense of feasibility in a sexual way. Dissatisfaction with a men's sex life is related to emotional discomfort. With the growth of sexual-neurotic feeling and sexual actions the desire for a technically perfect sexual act increases neglecting other aspects of relationships and partner's wishes. Women who are dependent on others tend to reject themselves and dissatisfaction with their sexual lives increases.

Conclusions. Male and female sexuality is associated with many factors of the individual's mental life. The experience of subjective well-being and quality of life includes sexual satisfaction.

Sexual nervousness is closely related to personal nervousness, which in turn is a set of negative emotions, expressed destructive and inconsistent personality traits, and impedes efficient social and psychological functioning. Sexual nervousness is defined
\end{abstract}


as dissatisfaction, disappointment in sex life that leads to neurotic sexual response - difficulties in controlling the sexual urge, confusion, anxiety, etc.

Key words: sexuality, sexual nervousness, libido, approaches to sex.

\section{INTRODUCTION}

$\mathrm{T}$

he research of sexuality features more and more permeates the field of psychological science and it is related not only to free expression of views on sexual sphere over the past decades but also to awareness of the importance of this sphere to measure the overall quality of life. Human sexuality has recently been under active consideration within the framework of psychological science and occupies a significant place in the life of every human being, the development and emergence of mankind. Sexuality, sexual relations are an integral part of every person and are essential to understanding the human being.

Sexuality is, to a certain extent, a driving force of human social activity, since it is aimed not only at sexual satisfaction but also social and psychological well-being related to improvement of life quality. Sex-related excitement defines the choice of behaviour, even in situations that are deliberately unrelated to sexual relations in a narrow sense. Sexuality is also a factor that encourages people to joint action and is one of the factors that bring people together and unite them, one of the main components of family life.

Sexuality of modern men and women is related to many factors concerning individual's mental life. Concerns about subjective well-being and quality of life include sexual satisfaction. Dissatisfaction with sexuality can also be related to nervousness, anxiety, propensity for various neurotic states and the like. Mark Allen and Emma Walter established that neuroticism is closely related to sexual dissatisfaction, negative emotions and symptoms of sexual dysfunction (Allen \& Walter, 2018) analysing a ratio of major dimensions of personality and components of human sexuality. The research, carried out by Joana Carvalho and Pedro Nobre (Carvalho \& Nobre, 2019) also indicates that there is a connection between neuroticism and sexuality. Hans Eysenck denotes dissatisfaction and disappointment concerning men's sex life that is related to neurotic sexual reaction as sexual nervousness (Eysenck, 2001, p. 51). But Ukraine still has little research on differences between sexual nervousness of men and women, so, the topic of psychological constitution of men and women sexual nervousness remains relevant.

\section{RESEARCH OF THE SEXUAL NERVOUSNESS}

The research was conducted with participation of 87 people aged 20 to 53 years, 44 men and 43 women ( $M=30.4$ years) in order to achieve the objective. The choice of psycho-diagnostic techniques is based on the tasks of the work: to study and analyse features of sexual nervousness of both men and women. 
A questionnaire was used «Instructions for sex» by H. Eysenck to determine sexual nervousness and personality traits concerning sex and sexual behaviour. The attitude toward sex was studied by the means of a questionnaire «Multidimensional approach to sex». As neurotic sexuality is often related to dissatisfaction with own sex life and other life spheres (Skrypnykov, 2015, pp. 141-142) (there was used an inventory) a questionnaire was used to examine the constitutions of psychological well-being of people involved «Psychological well-being scale» K. Riff. According to sex research of Andrii Skrypnykov, Larysa Herasymenko, Rustam Isakov social and psychological adaptation is related to sexual disadaptation and dissatisfaction with sex life, so the questionnaire technique of Karl Rogers, Rozalind Diamond was used to identify features of social and psychological adaptation and its relationship to neurotic reactions in sex life. Socio-demographic characteristics such as gender, age, education, marital status, family experience, presence of children, sibling position, income level, etc. were also taken into account.

Initially, average rates of sexual nervousness were compared among male and female groups. This comparison showed that women had a lower average level of sexual nervousness $(M=4.96 ; S D=0.43)$ than men $(M=5.43$; $S D=0.43)$ (Fig. 1).

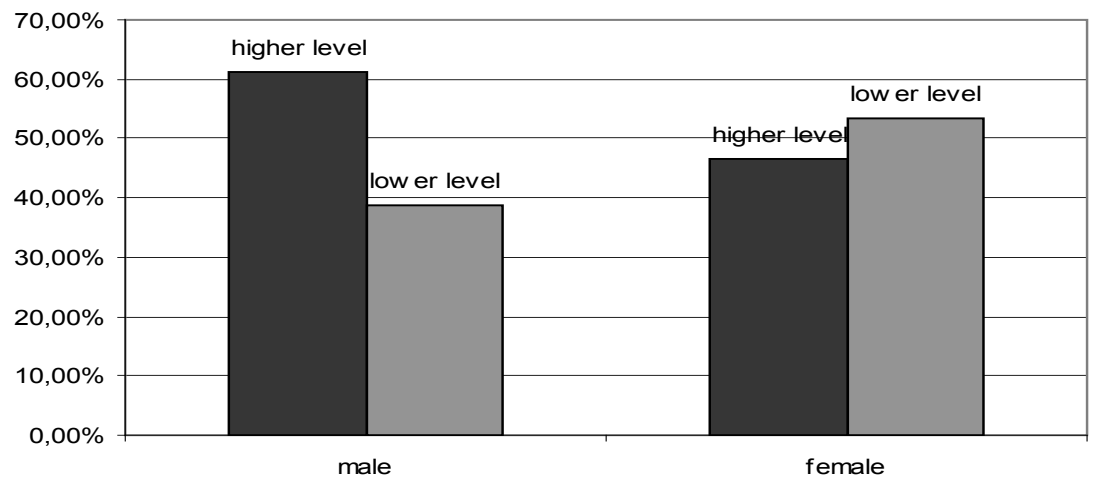

Fig. 1.

Percentage distribution of sexual nervousness levels between men and women.

Percentage distribution of levels concerning sexual nervousness (as this method used by $\mathrm{H}$. Eysenck «Instructions for sex» does not imply an average level of sexual nervousness, we used the techniques of "lower" and "higher" levels of sexual nervousness suggested by authors) makes it possible to claim, that women are characterised by a lower level of sexual nervousness compared to men, pointing to a higher level of sexual satisfaction. 


\section{DIFFERENCES OF SEXUAL NERVOUSNESS BETWEEN MEN AND WOMEN}

The common group of people interviewed was divided into two sub-groups according to gender and a comparative analysis was applied. The results, based on statistical comparisons of data, show that studied groups differ in such terms of sexuality and subjective wellbeing as: sexual nervousness $(p=0.023)$, pornography $(p=0.013)$, sexual arousal $(p=0.002)$, friendly approach to sex $(p=0.007)$, overall caring approach to sex $(p=0.030)$, positive relationships ( $\mathrm{p}=0.001)$, self-perception $(\mathrm{p}=0.008)$.

Men have a higher level of sexual nervousness and a higher level concerning pornography, sexual arousal and a caring approach to sex. Women are characterized by a higher level of friendly approach to sex. It may be assumed that men find it more difficult to control and suppress their sexual impulses, men's sexual thoughts and sexual behaviour are more likely to influence negative emotional experiences than women's.

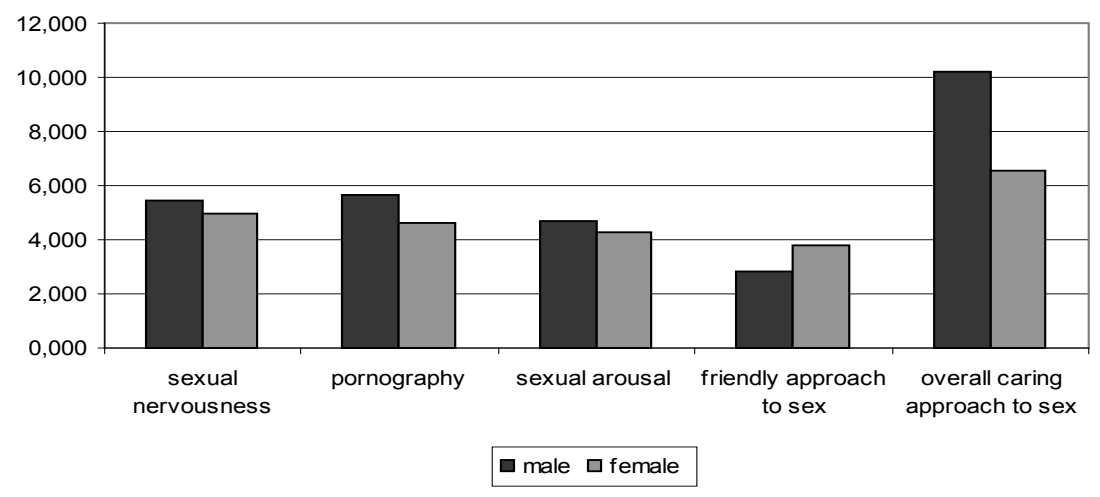

Fig. 2.

Comparison of sexuality index concerning men and women.

Higher level concerning "pornography" among men may indicate that they are more likely to enjoy sexually explicit photos or pictures, and they are more prone to pornography than women. Men are also more sexually aroused than women. At the same time a higher level of caring approach to sex indicates sensitivity in sex, consideration of partner's sexual needs, the desire for mutual pleasure having sex. Women, in turn, are characterized by a high level of sexual friendliness, indicating the importance of the intimate and communicative aspect of sex life. Therefore, for women, it is more important than for men to have a sense of friendship with sexual partner, to get to know him for a long time before sexual intercourse, to have good interpersonal relations and so on.

There are also differences between men and women in terms of subjective well-being such as positive relationships with others and self-acceptance. 
Women tend to care for others more than men. They are more prone to empathy, intimacy and compromise, focused on the establishment of trusting relationship. Women are also more likely to have a positive attitude towards themselves, their lives and their past than men.

Thus, the analysis of differences between men's and women's sexuality gives reason to claim that men have a higher level of sexual nervousness. It can be summarized that men are more emotionally affected by failures and difficulties in their sex lives, they are more eager to satisfy their own sexual preferences and they become sexually aroused more quickly. They are oriented towards not only their own sexual satisfaction but also to their partner's satisfaction as well. Women are more interested in developing sexual relationships in a friendly way, that is, in developing harmonious and trusting relationships with men. This is also indicated by a higher level of desire to have positive relationships with others in general. Women also have a higher level of self-acceptance, which indicates a more positive attitude towards themselves, their present and past lives. Such results can also be attributed to the influence of traditional gender stereotypes on sexual scenarios: sex is more important for men than for women because men have a higher biological level of attraction (the action of male sex hormones) and they are expected to be constantly ready for closeness. These are men who initiate sexual intimacy, women only accept or reject this initiative. Moreover, these gender stereotypes have a cultural versatility, as they can be found in American studies (Sakaluk, Todd et al., 2014). Traditionally, the physical component of sexuality is considered to be more important for men, and for women - expressive and romantic (acceptance by a partner, admiration, love).

\section{RESEARCH OF THE CORRELATES OF MEN'S AND WOMEN'S SEXUAL NERVOUSNESS}

Index of sexual nervousness that is measured in this study points to dissatisfaction and frustration with sex life, which in turn can lead to neurotic sexual reactions - difficulty controlling or suppressing sexual impulses, confusion over own thoughts or actions, etc. With the rise of sexual nervousness, dissatisfaction with one's sex life in general is also increasing. This is indicated by the correlation found between the scale of sexual nervousness and satisfaction with sex life. $(\mathrm{r}=-0.46)$. Also sexual nervousness is related to physical sex $(\mathrm{r}=0.37)$, impersonal sex $(\mathrm{r}=0.38)$, reversed with sexual feasibility $(\mathrm{r}=-0.29)$, which indicates a tendency for growing desire to get a sexual gratification by considering a partner only as an object to satisfy one's desire, an active focus on getting one's sense of pleasure. With the rise of sexual nervousness the desire to be a skilled lover is more important than other, more spiritual aspects of sexuality. The higher level of sexual nervousness is, the higher level the sex in the hierarchy of partnerships has. In addition, the sense of sexual feasibility decreases, that is, frustration in one's sex life increases. 
The individual's desire for psychological well-being and positive functioning is one of the driving forces of personal development, and a positive feeling of being full and focused on one's life is an important condition for a sense of satisfaction. However, there is a decline in psychological well-being with the increase in sexual nervousness. Thus, inversely to sexual nervousness there is related scale of psychological well-being $(\mathrm{r}=-0.27)$, goals in life $(\mathrm{r}=-0.36)$, personal growth $(\mathrm{r}=-0.28)$. The increase in sexual nervousness relates with the growth of frustration with oneself and implementation of own life plan. It can be assumed that the growing dissatisfaction with sex life is associated with the vagueness of one's own life goals, ambiguity concerning interests and plans, a sense of personal stagnation, the absence of a clear plan for personal development and discontent with life in general.

In addition, sexual nervousness is related to such aspects of socio-psychological adaptation as the desire to dominate $(\mathrm{r}=-0.26)$ and acceptance of others $(r=-0.33)$. The fact that sexual nervousness is on the increase is associated with difficulties in being open to accept the rights, values, judgments of others, a tendency to stereotype others and also evaluation of others in terms of their own system of values and priorities. So, the higher level of sexual nervousness is, the less desire to feel superiority over other people and the lower sense of self-worth compared to others, the passive acceptance of other people and the attitude towards them increase.

Thus, the correlation analysis in the general study group suggests that sexual nervousness is associated with dissatisfaction with sex life, the dominance of an "instrumental," "technical" attitude to sex life over other, spiritual aspects of sexuality. Sexual nervousness, however, is associated with a decline in a person's subjective well-being and difficulties in understanding other people's values.

A correlation analysis has also been carried out in two subgroups separately to identify men's and women's sexual nervousness.

Let's analyse the relationship of the studied indicators and the scale of sexual nervousness. The increase of men's and women's sexual nervousness is associated with a decrease in sexual satisfaction. That is, dissatisfaction, constant concern for the problems of sex life is associated with the feeling of frustration with your sex life. In addition, having an older sibling is also inversely related to sexual nervousness in men's $(r=-0.41)$ and women's $(r=-0.30)$ groups, which may be associated with the sibling position of the youngest child in family.

Peculiarities of sexual nervousness relationships in a group of men is a connection between dissatisfaction with sex life and a feeling of sexual nonfulfillment $(\mathrm{r}=-0.34)$, impersonal sex $(\mathrm{r}=0.47)$, physical sex $(\mathrm{r}=0.48)$, an exchange approach to sex $(\mathrm{r}=0.31)$, emotional discomfort $(\mathrm{r}=0.31)$, maladaptation $(\mathrm{r}=0.32)$, sharing approach to sex $(\mathrm{r}=0.31)$, emotional discomfort $(\mathrm{r}=0.31)$, disadaptiveness $(\mathrm{r}=0.32)$. As men become more neurotic concerning sex, the tendency to establish friendly relations with a partner $(r=-0.39)$, to set life goals $(r=-0.39)$, self-acceptance $(\mathrm{r}=-0.44)$, desire to dominate $(\mathrm{r}=-0.38)$, acceptance of other people $(r=-0.41)$ also declines. Men's sexual nervousness is inversely related to 
the presence of children $(r=-0.42)$. It can be assumed that paternity is an important moment of man's life and the presence of children is connected with the satisfaction of his own sex life, the absence of contradictions in the emotional feeling of sensual pleasures. The results also indicate that the real situation contradicts gender stereotypes regarding men's sexual scenarios. The instrumentality of male sexual behaviour and the prevalence of physical sex reduce the level of satisfaction with sex life and increase men's sexual neurotization.

Men with a deprived sense of superiority over others, a deprived sense of self-importance, reduced experience of self-fulfillment are less satisfied with their sex lives. Such dissatisfaction is associated with a critical, not always positive attitude towards oneself, a focus on one's own shortcomings, which is also reflected on difficulties in communicating with other people, acceptance of their otherness. This, in turn, is related to decline in emotional well-being and comfort in the emotional sphere. That is, men's sexual nervousness is associated with emotional distress and emotional discomfort. It can be assumed that satisfaction with the sex life is important for men to feel positive emotions. In addition, sexual nonfulfillment is associated with man's difficulty in setting goals and making life plans.

In men's sex life the exchange approach to sex grows and the friendly approach decreases, as sexual nervousness increases. That is, there is a tendency to devalue partner's personality by neurotic men. Sex becomes like a device for satisfying sensual desires in the absence of focusing on sexual partner. So, men's desire for pleasure is neurotic. There is also a tendency for actual sexual encounters to increase in the number with an increase in man's sexual nervousness.

Features of relationships concerning sexual nervousness in a group of women are sexual nervousness relationship and aggressive sex $(r=0.36)$. Therefore, it can be assumed that frustration with own sex life, the presence of neurotic women's sexual reactions are associated with the desire to humiliate a partner, hostility and aggressive impulses towards the partner.

Also, women's sexual neuroticism is inversely related to psychological well-being $(r=-0.33)$, self-acceptance $(r=-0.45)$ and dependence on others $(r=-$ 0.41 ) in relationships. That is, women are unhappy with their sex life and also with other aspects of their lives - self-fulfillment, relationships with others, life plans, personal growth and so on. This may indicate the importance of sexual sphere in woman's life. There are more sexually frustrated women that need support and approval of others and often rely on the values and beliefs of others. The increase in women's dissatisfaction and self-rejection are also related to women's sexual frustration and sexual nervousness. It can therefore be assumed that feelings of inferiority, depression and anxiety may be associated with negative emotional feelings concerning sex and make the quality of a woman's sex life worse.

A correlation analysis of the data shows that:

- Sexual nervousness is associated with an overall decrease in satisfaction with men's and women's sex lives. 
- The decline in psychological well-being, the lack of a clear plan and goals in life and personal growth are associated with the feelings of sexual nonfulfillment.

- In men's sex life an exchange approach to sex increases with the growth of sexual neurotic tendencies a mechanistic, impersonal perception of a partner.

- Men's sexual nervousness is closely related to emotional discomfort.

- Men with low self-esteem have lower self-acceptance and more sexual-neurotic reactions.

- Dependent women who have a lower level of positive self-esteem tend to be sexually unfulfilled and dissatisfied, may have a higher level of aggressive sex and a desire to humiliate their sexual partner.

\section{ANALYSIS OF THE FACTOR STRUCTURE OF MEN'S AND WOMEN'S SEXUAL NERVOUSNESS}

Factor analysis was used to determine the structure of man's and woman's sexual nervousness for the two studied groups. Indicators of sexual attitude, approach to sex, psychological well-being and socio-psychological adaptation were eligible for factorization.

Therefore, factor analysis in the study group of men explains $57.39 \%$ of the total dispersion of factors and 6 factors were identified during the analysis.

The first factor includes sexual satisfaction (-0.623), disadaptation (0.782), acceptance (-0.551) and self-rejection (0.867), external control (0.810), escapism $(0.628)$, acceptance of others $(-0.707)$, internality $(-0.846)$ and desire for dominance (-0.801). Factor has received the name «Sexual satisfaction» and explains $15.61 \%$ of data total dispersion. Combining these indicators into one factor confirms the relationship between sexual satisfaction, positive attitude towards oneself and others, taking responsibility. It can be assumed that self-esteem and sexual well-being for a man are important. At the same time, the backward links between pleasure in one's own sex life and disadaptation, escapism, and external control point to a link between negative emotional expressions and discontent with one's sexuality.

The second factor "Sexual Nervousness" describes $9.89 \%$ of the data dispersion, and included such indicators as sexual implementation (-0.564), sexual nervousness (0.785), aggressive sex (0.566), romantic approach to sex (-0.531), emotional discomfort (0.501). This suggests that a man's sexual nervousness is related to the desire to dominate and suppress the partner, which also affects a person's emotional discomfort. On the contrary, a sense of man's sexual nonfulfillment is associated with enthusiasm, romantic and gentle attitude towards a partner.

The third factor that describes $8.51 \%$ of the total data dispersion was named "Sexual Permissiveness" because it included such scales as sexual permissiveness (0.749), impersonal sex (0.720), sexual arousal (0.729), sexual libido (0.899). 
It is important for men to have a sense of modern free attitude towards sex, strong sexual desire, and sexual sensitivity.

The fourth factor «Social characteristics» included indicators of socio-demographic approach to sex as well as exchange-careful approach (0.532), and this factor describes $7.14 \%$ data dispersion. It can be assumed that for men that have children (0.808), a certain family experience (0.745), a high income level (0.502) are important for the intimate partner's feelings, the desire for positive reactions and equal sexual pleasure.

The fifth factor "Approach to Sex" that describes 6.73\% of the total data dispersion included indicators of a caring approach to sex (0.682) and emotional comfort (0.585). That is, men who consider the needs and feelings of a partner in sex are characterized by emotional comfort and a state of emotional comfort in the relationship.

The sixth factor describes $4.95 \%$ of the total dispersion of the data obtained and has received the name «Psychological well-being». It includes indicators of pornography (-0.637), autonomy (0.623), environmental management (0.588), goals in life (0.864), self-acceptance (0.514) and personal growth (0.727). That is, men who are positive towards themselves, have goals or feelings of direction in their lives, strive for independence and autonomy are free to use pornographic content.

Factor analysis was also carried out in a group of women. In this case, seven factors which describe $57.23 \%$ of the data dispersion.

Women's sexual nervousness is associated with nervousness and embarrassment in dealing with people of the opposite sex, as well as the constant need for support and approval from other people. Satisfaction with women's sex life is related to feelings of fulfillment in sexual relations. This is indicated by the results of factor analysis, as well as the correlation analysis described above. Thus, the first factor "Sexual Nervousness" which explains $13.9 \%$ of total data dispersion contains indicators of sexual fulfillment (0.540), sexual nervousness (-0.555), sexual shyness (-0.637), satisfaction (0.622) and tendency to obey $(-0.603)$. There is also an inverse correlation between sexual satisfaction and sexual nervousness $(\mathrm{r}=-0.40)$ in a group of women.

Such indicators as sexual permissiveness $(-0.635)$, impersonal sex $(-0.746)$, pornography (-0.626), sexual arousal (-0.731), aggressive sex (-0.693), sexual libido (-0.867), masculinity (-0.879) were included in the second factor in mentioned group "Sexual permissiveness" and it explains $10.66 \%$ of the data dispersion. That is, masculine women have an optimal attitude to pornographic products, they do not have an excessive amount of stereotypes about sexuality, they have strong sexual libido.

The third factor "Self-acceptance" explains $7.78 \%$ of total data dispersion and contains indicators of self-acceptance $(-0.834)$, acceptance of others $(-0.893)$, emotional comfort (-0.861), internality -0.831$)$, desire for dominance $(-0.697)$ with negative contributions. That is, women who are inclined to understand themselves are kind to other people and do not want to feel superior to others.

The fourth factor "Social characteristics" describes $7.63 \%$ of the total data dispersion and includes the socio-demographic characteristics of the individu- 
als surveyed (-0.800 to -0.608). It is worth noting that this factor did not include indicators of sexuality, unlike the factor analysis in the male group, so it can be assumed that socio-demographic indicators have a weaker correlation with women's sexuality.

The fifth factor "Socio-psychological adaptability" explains $6.59 \%$ of the data dispersion and K. Rogers and R. Diamond indicators of socio-psychological adaptability ( -0.784 to 0.814$)$ are combined there. This factor points to the importance of a harmonious attitude to oneself and a positive relationship with others for a prosperous life.

The sixth factor "Psychological well-being" describes $6.1 \%$ of data dispersion and it includes indicators that describe the feelings of subjective wellbeing of the person (from 0.604 to 0.759 ).

The seventh factor is "Approach to Sex" that describes 4.54\% of the data dispersion. It contains indicators of physical sex $(-0.538)$ as well as practical $(-0.671)$, proprietary $(-0.592)$, altruistic $(-0.712)$ approaches to sex. That is, confidence in a sexual partner, a penchant for self-sacrifice, and at the same time some jealousy are important to women..

So the results gave an opportunity to describe the fullness of the components concerning sexuality of men and women. These factors suggest that sexual nervousness is related to satisfaction rates for sexual and other aspects of person's life. For both men and women, the inverse relationship between sexual nervousness and the sense of sexual fulfillment has been common. So, both men and women are frustrated by their own sexual relations when they feel negative emotions related to sex.

Table 1

Features of sexual nervousness of men and women

\begin{tabular}{cc}
\hline Men & Women \\
\hline $\begin{array}{c}\text { Sexual nervousness is related to } \\
\text { aggressive sex and emotional discomfort }\end{array}$ & $\begin{array}{c}\text { Sexual nervousness is related to sexual } \\
\text { shyness and tendency to obey } \\
\text { Theing sexually neurotic rules out a } \\
\text { romantic approach to sex }\end{array}$ \\
$\begin{array}{c}\text { The } \\
\text { related to the feeling of dissatisfaction } \\
\text { with their own sex life }\end{array}$ \\
$\begin{array}{c}\text { Source: own research. }\end{array}$
\end{tabular}

The peculiarities of men's feeling of sexual nervousness are the tendency to aggression in sexual relations, that is, the desire to dominate the sexual partner, the lack of romance in the relationship and the simultaneous feeling of anxiety and dissatisfaction. There is determined fact in a group of women based on factor analysis that claims about shy women who tend to obey others, who seek support and approval, feel discontent with their sex lives. 


\section{CONCLUSIONS}

As a result of summarizing existing views on the content of sexuality concept, personal and sexual nervousness as a complex psychological formation, sexuality is defined as a set of mental and physiological reactions, feelings and actions, to express and satisfy sexual desires. Sexuality is a set of personality traits and characteristics. It is related not only to the process of achieving sexual satisfaction but also to the overall subjective well-being of the individual. That is, sexuality is not only a self-fulfillment of sexual function, but it also includes numerous psychological representations: imaginations, desires, motivations, cognitions, emotions and so on.

Sexual nervousness is closely related to personal nervousness, which in turn is a set of negative emotions, expressed destructive and inconsistent personality traits, and impedes efficient social and psychological functioning. Sexual nervousness is defined as dissatisfaction, disappointment in sex life that leads to neurotic sexual response - difficulties in controlling the sexual urge, confusion, anxiety, etc.

Features of sexuality that is related to the sex of the person and its psychological characteristics are becoming relevant in the current conditions concerning transformation of society values. The role of men and women in society is changing. Gender expectations and stereotypes extend to the sexual sphere. Research on sexual nervousness of men and women is therefore a relevant aspect to study the sexuality of the individual.

The statistical analysis that was carried out and made it possible to draw conclusions on the sexual nervousness of men and women. It has been established that there are differences between men and women in terms of sexual nervousness, attitudes towards pornographic materials, sexual arousal, friendly and exchange approaches to sex, signs of positive relationships with others and self-acceptance. The results of the comparative analysis suggest that men are more focused on careful approach to sex. That is, they tend to take into account and fulfill needs of the partner and their own needs. Women, in turn, are more focused on a friendly approach to sex, that is, to have a warm and intimate relationship with a sexual partner. Men are more loyal to pornographic products and they reach sexual arousal faster having higher level of sexual nervousness.

The results of correlation and factor analyzes indicate that sexual satisfaction for both men and women is related to reduction in sexual nervousness and to increase in a sense of feasibility in a sexual way. At the same time dissatisfaction with a men's sex life is related to emotional discomfort. The desire for a technically perfect sexual intercourse increases neglecting other aspects of relationships and partner's wishes with the growth of sexual-neurotic feeling and sexual actions. Women that are dependent on others tend to reject themselves and dissatisfaction with their sexual lives increases. Sexual nervousness is related to the perception that both men and women do not fulfill their sexual potential. 


\section{REFERENCES}

[1] Allen, M. S., \& Walter, E. E. (2018). Linking big five personality traits to sexuality and sexual health: A meta-analytic review. Retrieved from https:// doi.org/10.1037/ bul0000157

[2] Barnes, G. E. \& Malamuth, N. M. (1998). Eysenck's Theory of Personality and Sexuality. Retrieved from https://pdfs.semanticscholar.org/7f03/bd7c2c8c844668a08c0e240afd522652bf7e. pdf?_ga=2.169928227.2063132341.1579858725-703274801.1579858725

[3] Carvalho, J., \& Nobre, P. J. (2019). Five-Factor Model of Personality and Sexual Aggression. Retrieved from https://journals.sagepub.com/doi/abs/10.1177/0306624X13481941

[4] Eysenck, Hans J. (1976). Sex and Personality. London: Open Books Ltd.

[5] Eysenck, Hans J. (2001). Исследования человеческой психики [Studies of the human psyche]. Moscow: Изд-во ЭКСМО-Пресс

[6] Modgil, S., \& Modgil, C. (2012). Hans Eysenck: Consensus And Controversy. London: The Falmer Press

[7] Sakaluk, J. K., Todd, L. M., Milhausen, R. \& Lachowsky, N. J. Undergraduate Research Group in Sexuality. (2014). Dominantheterosexual sexual scripts in emerging adulthood: Conceptualizationand measurement. Journal of Sex Research, 51, 516-531. doi:10.1080/00224499.2012.745473

[8] Skrypnykov, A. (2015). Ефективність та доцільність проведення сімейної психотерапії при невротичних розладах у жінок [Effectiveness and appropriateness of conducting family psychotherapy in neurotic disorders in women]. Retrieved from http://elib.umsa.edu.ua/bitstream/umsa/5429/1/The\%20effectiveness $\% 20$ and $\% 20$ feasibility $\% 20$ of $\% 20$ family $\% 20$ psychotherapy \%20with\%20neurotic\%20disorders $\% 20$ in $\% 20$ women.pdf 